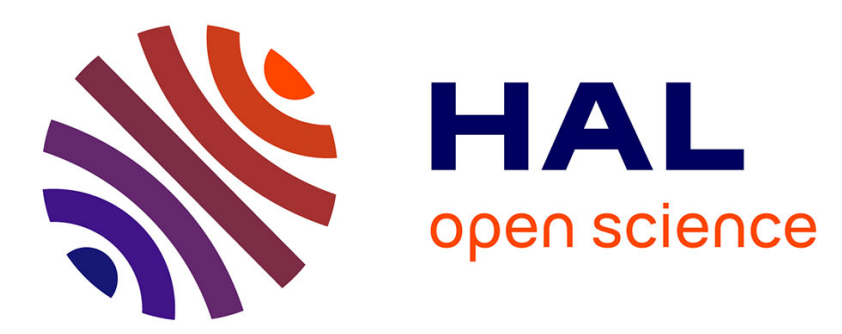

\title{
The Influence of Native-Language Phonology on Lexical Access: Exemplar-Based Versus Abstract Lexical Entries
}

Christophe C Pallier, Angels Colomé, Núria Sebastián-Gallés

\section{To cite this version:}

Christophe C Pallier, Angels Colomé, Núria Sebastián-Gallés. The Influence of Native-Language Phonology on Lexical Access: Exemplar-Based Versus Abstract Lexical Entries. Psychological Science, 2001, 12 (6), pp.445-449. 10.1111/1467-9280.00383 . hal-02341190

\section{HAL Id: hal-02341190 \\ https://hal.science/hal-02341190}

Submitted on 31 Oct 2019

HAL is a multi-disciplinary open access archive for the deposit and dissemination of scientific research documents, whether they are published or not. The documents may come from teaching and research institutions in France or abroad, or from public or private research centers.
L'archive ouverte pluridisciplinaire HAL, est destinée au dépôt et à la diffusion de documents scientifiques de niveau recherche, publiés ou non, émanant des établissements d'enseignement et de recherche français ou étrangers, des laboratoires publics ou privés. 


\title{
The influence of native-language phonology on lexical access: exemplar-based vs. abstract lexical entries
}

\author{
Christophe Pallier \\ Angels Colomé and Núria Sebastián-Gallés \\ Laboratoire de Sciences Cognitives et Psycholinguistique, Dept de Psicologia Bàsica, Universitat de Barcelona, Spain \\ CNRS-EHESS, Paris, France
}

\begin{abstract}
This is the penultimate draft of a paper in press in Psychological Science (as of March 2001)
This study uses medium-term auditory repetition priming to investigate word recognition processes. Highly fluent Catalan-Spanish bilinguals whose first language was either Catalan or Spanish were tested in a lexical decision task involving Catalan words and non-words. Spanishdominant individuals, but not Catalan-dominant individuals, exhibited repetition priming for minimal pairs differing in only one feature that was non-distinctive in Spanish (e.g. /netə/ vs. $/ \mathrm{n} \varepsilon \mathrm{t} /$ /), thereby indicating that they processed them as homophones. This finding provides direct evidence both that word recognition uses a language-specific phonological representation and that lexical entries are stored in the mental lexicon as abstract forms.
\end{abstract}

Correctly perceiving and producing the sounds of a second language is a very difficult task, as evidenced both by widespread anecdotal evidence and by a number of formal studies (see Strange 1995 for a review). Problems of this kind are observed even in those who have been exposed to the second language for considerable periods of time and who have therefore had plenty of opportunities to learn its sounds (Flege, Yeni-Komshian, \& Liu, 1999; Mack, 1989; Pallier, Bosch, \& Sebastián-Gallés, 1997a; Sebastián-Gallés $\&$ Soto-Faraco, 1999). It has been suggested that our nativelanguage phonological system acts as a "sieve", filtering out the properties in the speech signal that our first language (L1) system cannot properly accommodate (Polivanov, 1932; Trubetzkoy, 1939/1969). However, the ease with which foreign sounds are perceived varies; the degree of difficulty depends on the perceived phonetic similarity between L1 and L2 sounds (Best, 1995; Flege, 1995). Similar, but not identical, L2 sounds and L1 phonemic categories are particularly difficult to perceive. Among the best known examples of this are the problems that Japanese listeners experience in distinguishing English /r/ and /1/ phonemes, which are both mapped to Japanese /1/ (Goto, 1971; McClelland, Thomas, McCandliss, \& Fiez, 1999). Here we consider the consequences for lexical representations when L2 learners have difficulties in creating separate phonetic categories for certain L2 sounds. It is reasonable to expect that a minimal pair of L2 words differing only in one phoneme contrast (i.e.

This research was supported by Spanish MEC research Grant PB97-977 and Catalan Government research grant GR00083. Special thanks are due to Anne Christophe and Albert Costa for constructive comments on previous versions of this paper. We also thank Anna Capdevila for her help in preparing the materials. A preliminary report of this study was given at the Sixth Eurospeech meeting (Budapest, Hungary), September 1999. "rock"-“lock") will be represented in the same way by L2 learners who do not possess the $/ \mathrm{r} /-/ 1 /$ contrast. Indeed, if both L 2 phonemes are assimilated to the same L1 phoneme, then the two words become homophones.

Previous research in L2 phonemic perception has not addressed this issue; to date, studies in the field have focused on phonemic perception per se. Participants typically have to decide consciously whether a given speech sound corresponds to a given category (e.g. an identification task), or matches another speech sound (e.g. a same-different task). In fact, several studies have shown that the acoustic-perceptual system does not lose its ability to perceive the acoustic differences between non-native contrasts (Mann, 1986; Miyawaki et al., 1975; Werker \& Tees, 1984). The fundamental difference between native (skilled) and non-native (less-skilled) speech perception mechanisms seems to lie in the fact that the former focus their attention on a more abstract (linguistic) level than the latter. This would seem to suggest that the difficulties L2 learners encounter with some foreign contrasts have an attentional, rather than a perceptual, origin (Flege, 1995; Jusczyk, 1993; Lively, Pisoni, Yamada, Tohkura, \& Yamada, 1994; Mayberry \& Eichen, 1991). In these circumstances, it is not a priori impossible that some of this acoustic/phonetic information might percolate into the lexicon. Likewise, it is conceivable that bilinguals, despite their lack of sensitivity to certain L2 contrasts when performing certain (conscious) phonemic perception tasks, might be sensitive to the same contrasts when identifying words. In fact such a possibility would be consistent with models of the lexicon in which words are stored directly as concrete exemplars. Models of lexical representation can be distinguished on the basis of their representational format. Some models propose that words are represented in the lexicon in the form of abstract phonological representations (McClelland \& Elman, 1986; Norris, 1994). According to others, word-forms are stored in the brain in the form of detailed acoustic traces (Goldinger, 1992,1996; Klatt, 1979, 1981; Pisoni, 1996). 
Proponents of the "acoustic trace" theory claim that word recognition involves a "direct" comparison between the memorized acoustic pattern and that elicited by the current acoustic signal. Each word is associated to many acoustic tokens and word recognition consists in finding the nearest match in a vast collection of word-forms. Experimental evidence supporting this view has shown that participants are very sensitive to non-linguistic surface cues in word recognition tasks, such as speaker's voice (Goldinger, 1996, Schacter \& Church, 1992; see Pisoni, 1996 for a review). As discussed above, previous research on second language speech perception has shown that the speech perceptual system does not lose its capacity to perceive correctly the acoustic properties of the speech signal because of the acquisition of the first language phonological system, and thus it is able to acoustically perceive new non-native contrasts. If word-forms are stored in the mental lexicon in an acoustic format and perception of L2 contrasts preserves this information, the episodic view of the mental lexicon predicts that instances of L2 minimal pairs will not share the same acoustic- lexical representation, and, accordingly, they should not be processed as homophones. The model in which words are represented as abstract phonological entities proposes the opposite. In this model, the acoustic speech stream is coded as a normalized, language-specific phonological representation (which may consist of features, phonemes, syllables or a combination of these). This prelexical phonological representation is used for matching with lexical representations. Whenever a pair of L2 phonemes are assimilated to the same L1 phoneme, their representation will become identical at the prelexical level: the L1 phoneme will be used for coding both L2 speech sounds. Consequently, two L2 words which differ only in such a contrast will receive exactly the same lexical representation, in which the L1 phoneme takes the place of both L2 phonemes. Therefore, the two L2 words would be functionally homophones.

In previous studies (Bosch, Costa, \& Sebastian-Gallés, 2000; Bosch, Costa, \& Sebastián-Gallés, 1994; Pallier et al., 1997a; Sebastián-Gallés \& Soto-Faraco, 1999) we identified two groups of highly skilled Spanish-Catalan bilinguals with a comparable (if not fully equivalent) command of both languages at the lexical level, but who show significant differences in the phonemic representations of the two languages. Spanish and Catalan are two Romance languages that differ at the segmental level, both in their vowel and consonant repertoires. Spanish has five vowels: /a/, /e/, /i/, /o/ and /u/, and Catalan has eight: /a/, /e/, / $/ \mathrm{l} / \mathrm{i} / \mathrm{/}, / \mathrm{o} /$, $/ \mathrm{J} / \mathrm{/u} /$ and $/ \partial /$. Spanish does not have voiced fricatives in their phoneme repertoire, but has unvoiced fricatives that do not exist in Catalan (such as $/ \theta /$ and $/ \mathrm{x} /$ ). Catalan has both voiced fricatives (such as /z/ and / $/ 3 /$ ) and unvoiced fricatives (some of the latter not appearing in Spanish, such as /z/). In these experiments it was observed across a wide range of tasks that most Spanish-dominant bilinguals fail to perceive Catalan contrasts that do not exist in Spanish (e.g. the vowel contrast /e/-/ع/). In these studies, all participants had been born in Barcelona (Spain) or in its metropolitan area (where both languages are spoken), had received the same bilingual education, and were currently extensively exposed to both languages. The basic difference between the groups was that Spanish-dominant bilinguals had been raised in a monolingual Spanish environment before attending kindergarten while Catalan-dominant bilinguals had been raised in monolingual Catalan environments.

This study explored lexical access in the group of Spanishdominant bilinguals, who are nevertheless extremely fluent in Catalan. Their performance was compared with that of a Catalan-dominant group of Catalan-Spanish bilinguals. We selected the repetition priming task as a suitable tool for studying the format of lexical representations. In this paradigm, participants are asked to perform lexical decisions on lists of stimuli, some of which appear twice. When a word is encountered for a second time, participants respond more rapidly than when it occurs the first time. If the repeated stimulus is a non-word, no difference is recorded in participant decision times. Therefore, this task is considered to tap lexical information. For our bilingual population, the crucial comparison rests on minimal pairs of Catalan words which differ in only one Catalan-specific contrast, such as /netə/-/netə/ (meaning "granddaughter" and "clean", fem). Catalan-dominant bilinguals would be expected to process these words as being quite distinct (which indeed they are) and to show no facilitation for the second word of a pair. The Spanish-dominant participants, on the other hand, would be expected to exhibit one of two behaviors: either they would behave in exactly the same way as the Catalan dominants (no facilitation for the second word), or they would behave as if the words were real homophones (as much facilitation as for a repetition).

In our experiment, participants were asked to perform an auditory lexical decision task on lists that contained minimal pairs of Catalan words, comprising three Catalan-specific contrasts. As already mentioned, previous research has shown that Spanish-dominant bilinguals have difficulty in perceiving these contrasts (Pallier et al., 1997a; SebastiánGallés \& Soto-Faraco, 1999): /e/-/ع/,/o/-/ó/ and /s/-/z/. Thus, for example, the Catalan word /netə/ (meaning "clean" f.) was followed lower down the list by the stimulus /neta/ (meaning "granddaughter"). If these pairs of Catalan words, such as /netว/-/neta/, are stored in the mental lexicon as homophones, Spanish-dominant bilinguals should treat /netə/ as a repetition of /netə/, while Catalan-dominant bilinguals should treat them as separate phonological lexical entries.

\section{Method}

\section{Material}

The stimuli were Catalan words and pseudo-words. Fortyeight words forming twenty-four minimal pairs based on phonemic contrasts specific to Catalan were included, as well as sixteen words forming eight minimal pairs based on contrasts that exist both in Spanish and in Catalan (see appendix). In addition, sixty-four Catalan pseudo-words were created that formed thirty-two minimal pairs following the same patterns as the preceding words. Finally, 152 words 
and pseudo-words were also included to serve as filler items. Four counterbalanced lists of 280 stimuli were created in the following way: In each list, one member of each minimal pair appeared (e.g. /netə/ from /netə/- /neta/) and was followed, 8 to 20 items further down in the list, either by the other item in the minimal pair (e.g. /netə/), or by itself (e.g. /netə/). The members of a given minimal pair appeared in the same positions in all four lists, but were counterbalanced across the lists.

\section{Procedure}

The participants were tested individually in sound attenuated booths. The presentation of the stimuli was fully controlled by Hewlett Packard personal computers, equipped with Pro-Audio 16 sound cards. Auditory stimuli were presented through Sennheiser HMD224x headphones with an ISI of 2.5 seconds. The experimental situation was controlled by the program EXPE (Pallier, Dupoux \& Jeannin, 1997b).

\section{Participants}

Sixty-four undergraduate Psychology students from the University of Barcelona participated in the experiment in exchange for course credits. All were fluent bilingual speakers of Spanish and Catalan. Half were born in Catalanspeaking families, and half were born in Spanish-speaking families. All participants had learnt their second language (either Spanish or Catalan) from an early age (in the latest case beginning at the age of six).

\section{Results}

We defined a "repetition effect" as the reaction-time decrease between the first and the second occurrences of an item (condition "same") or between the occurrences of an item and its counterpart in a minimal pair (condition " minimal pair"). Reaction times to the second occurrence were subtracted from the reaction time to the first, therefore a positive value means a repetition effect. The average "repetition effects" are plotted on Figure 1, as a function of the following factors: Language dominance of the participants (Catalan vs. Spanish), Condition (same vs. minimal pair), Contrast type (Catalan-specific vs. Common contrast) and Lexical status (Words vs. Pseudo-words). The 95\% confidence intervals displayed are based on the subject-based Anovas, but the item-based Anovas lead to the same conclusions concerning significance. These figures reveal significant repetition effects only for words in the condition "same" for both populations and, in the condition "minimal pair", only in the Spanish-dominant group for the Catalan-specific contrasts. These analyses are corroborated by the fact that the Condition $\times$ Language interaction, restricted to words, was significant for Catalan-specific contrasts (interaction in Figure $1 \mathrm{~A}: \mathrm{F} 1(1,56)=4.2, \mathrm{p}<.05 ; \mathrm{F} 2(1,21)=4.2, \mathrm{p}=.05)$, but not for Common contrasts (interaction in figure $1 \mathrm{~B}$ : both $\mathrm{Fs}<1$ ). There was no effect of Repetition on the pseudowords.

Analyses performed on absolute reaction times revealed a main effect of Lexical status (with RTs to pseudowords be- ing 60 msec slower than RTs to real words $(\mathrm{F} 1(1,56)=57.7$, $\mathrm{p}<.001$ and $\mathrm{F} 2(1,56)=6.6, \mathrm{p}<.05)$. The effect of Language Dominance was not significant (Catalan-Dominant: $921 \mathrm{~ms}$

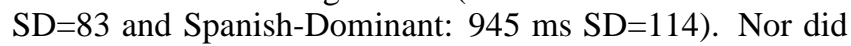
error analyses yield any significant results.

\section{Discussion}

The results of this experiment revealed clear-cut processing differences between the populations of participants tested. More specifically, both groups exhibited a repetition effect for a "Same" repetition, but not when a minimal change intervened between the first and the second occurrence of an item. The crucial test condition involved minimal pairs of Catalan words that differed only in one contrast that was not present in Spanish (e- $\varepsilon, 0-0, \mathrm{~S}-\mathrm{z})$. In such cases, Spanish native speakers showed a repetition facilitation of the same amplitude as that observed for a real repetition. In contrast, the Catalan-dominant bilinguals did not show any repetition effect for these minimal pairs. It should be stressed, however, that the Spanish-dominant bilinguals achieved a high performance in the lexical decision task with Catalan words: their reaction times and error rates were not significantly different from those of Catalan natives. In short, our experiment shows that some pairs of Catalan words are processed as homophones by Spanish-dominant bilinguals, even though they master Catalan very well and their performance on a lexical decision task in Catalan is equivalent to that of natives. We can conclude, therefore, that although Spanish bilinguals master the Catalan lexicon, their lexical representations differ from those of native Catalans.

The implications of these results are twofold. First, the data presented here show that the lack of sensitivity to difficult L2 phonemic contrasts is not due to the particular properties of the tasks employed in L2 phoneme perception experiments, but that this lack of sensitivity extends into the way L2 words are represented in the mental lexicon. If listeners have difficulties in perceiving an L2 phonemic contrast, they will represent L2 word pairs with that contrast as homophones.

Second, the present data contribute to the on-going debate concerning the general format of the mental lexicon. Contrary to the predictions of the episodic view of the mental lexicon, and in agreement with abstractionist models, instances of L2 minimal pairs have been processed as homophones. Yet, one possible way for episodic models to account for the present data would be to assume that words are stored in an acoustic format ("language-free"), but that the metric of comparison depends on the language of the listener. Therefore, bilingual speakers would perceive speech sounds (acoustically) in the two languages in the same way, but how this information is retrieved in the brain would differ in the way the different acoustic parameters are employed. Following these notions, episodic models could postulate that lexical representations in Catalan and Spanish dominant listeners would not differ (they would contain both linguistic and non-linguistic information), but the way this information is retrieved from the lexicon would be language-dependent. Though this is not an impossible scenario, this theory would 
a.

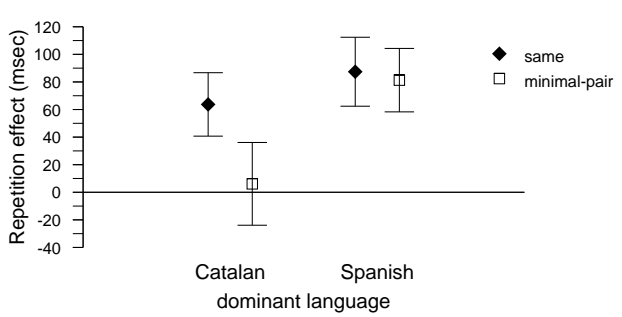

C.

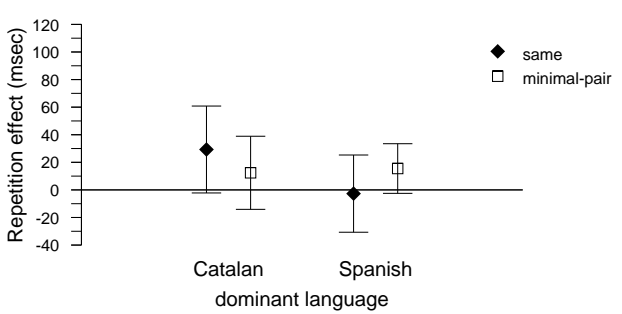

b.

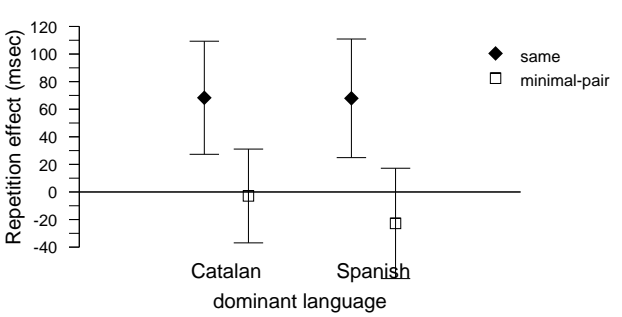

d.

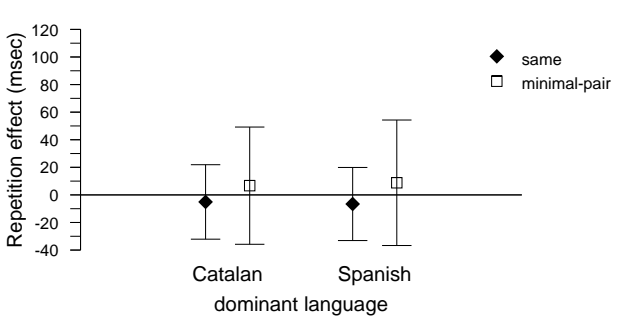

Figure 1. Repetition effect as a function of language, condition, contrast type and lexical status. Panels: a.) words with catalan-specific contrasts; b.) words with common contrasts; c.) pseudowords with catalan-specific contrasts; d) pseudowords with common contrasts (error bars show $95 \%$ conf. intervals)

have to explain a number of complex points before it could be accepted. For example, it has to explain how the retrieval mechanism, very sensitive to acoustic properties of the input (such as changes in speakers' voice, see Goldinger, 1996) remains insensitive to massive acoustic properties of the speech signal in the second language; i.e., it has to account for how, in spite of mastering a second language lexicon (reaction time and error rates differences were not significant in the two populations under study), the metric of comparison of Spanish dominant listeners does not change to conform to Catalan (second language) properties.

To conclude, the fact that Spanish-dominant bilinguals processed Catalan-specific minimal pairs as homophones favors the view that lexical representations consist of abstract language-specific phonological representations. In addition, it seems that this abstract phonological code, once acquired, is hard to modify. Even though the Spanish-dominant bilinguals in the experiment had had at least 15 years of exposure to Catalan at the time of testing, and had attained a high degree of performance in Catalan, they had not been able to learn the Catalan-specific contrasts. The results also suggest that although acoustic information may be available to the speech perception system, it does not percolate into the lexicon.

\section{References}

Best, C. T. (1995). A direct realist view of cross-language speech perception. In W. Strange (Ed.), Speech Perception and Linguistic Experience (pp. 171-206). Baltimore, MD: York Press.

Bosch, L., Costa, A., \& Sebastian-Gallés, N. (2000). First and second language vowel perception in early bilinguals. European Journal of Cognitive Psychology.

Bosch, L., Costa, A., \& Sebastián-Gallés, N. (1994). La estructura interna de las categorías fonéticas: percepción de vocales e identificación de prototipos en catalán y español. Paper presented at the XII Congreso Nacional AESLA: Nuevos horizontes de la lingüística, Barcelona, Spain.

Flege, J. E. (1995). Second language speech learning: Theory, findings and problems. In W. Strange (Ed.), Speech Perception and Linguistic Experience (pp. 233-272). Baltimore, MD: York Press.

Flege, J. E., Yeni-Komshian, G. H., \& Liu, S. (1999). Age constraints on second-language acquisition. Journal of Memory and Language, 41, 78-104.

Goldinger, S. D. (1992). Words and voices: Implicit and explicit memory for spoken words. Unpublished $\mathrm{PhD}$, Indiana University.

Goldinger, S. D. (1996). Words and voices: Episodic traces in spoken word identification and recognition memory. Journal of Experimental Psychology: Learning, Memory, \& Cognition, 22(5), 1166-1183.

Goto, H. (1971). Auditory Perception by normal Japanese adults of the sounds "l" and "r". Neuropsychologia, 9, 317-323.

Jusczyk, P. W. (1993). From general to language-specific capacities: the WRAPSA Model of how speech perception develops. Journal of Phonetics, 21, 3-28.

Klatt, D. H. (1979). Speech perception: A model of acousticphonetic analysis and lexical access. Journal of Phonetics, 7, 279-312.

Klatt, D. H. (1981). Lexical Representations for Speech Production and Perception. In T. Myers, J. Laver, \& J. Anderson (Eds.), The Cognitive Representation of Speech (pp. 11-31). Amsterdam: North-Holland Publishing Company.

Lively, S. E., Pisoni, D. B., Yamada, R. A., Tohkura, Y., \& Yamada, T. (1994). Training Japanese listeners to identify English /r/ and /1/ III. Long-term retention of new phonetic categories. Journal of the Acoustic Society of America, 96, 2076-2087.

Mack, M. (1989). Consonant and vowel perception and production: Early English-French bilinguals and English monolinguals. Perception and Psychophysics, 46, 189-200.

Mann, V. A. (1986). Distinguishing universal and languagedependent levels of speech perception: Evidence from Japanese 
listeners' perception of English [1] and [r]. Cognition, 24, 169196.

Mayberry, R., \& Eichen, E. (1991). The long-lasting advantage of learning sign language in childhood: Another look at the critical period for language acquisition. Journal of Memory and Language, 30, 486-512.

McClelland, J. L., \& Elman, J. L. (1986). The TRACE models of speech perception. Cognitive Psychology, 18, 1-86.

McClelland, J. L., Thomas, A., McCandliss, B. D., \& Fiez, J. A. (1999). Understanding failures of learning: Hebbian learning, competition for representational space, and some preliminary experimental data. In J. Reggia, E. Ruppin, \& D. Glanzman (Eds.), Brain, behavioral and cognitive disorders: The neurocomputational perspective . Oxford: Elsevier.

Miyawaki, K., Strange, W., Verbrugge, R. R., Liberman, A. M., Jenkins, J. J., \& Fujimura, O. (1975). An effect of linguistic experience: The discrimination of $[\mathrm{r}]$ and $[1]$ by native speakers of Japanese and English. Perception and Psychophysics, 18, 331340.

Norris, D. (1994). Shortlist: A connectionist model of continuous speech recognition. Cognition, 52(3), 189-234.

Pallier, C., Bosch, L., \& Sebastián-Gallés, N. (1997a). A limit on behavioral plasticity in vowel acquisition. Cognition, 64, B9B17.

Pallier, C., Dupoux, E., \& Jeannin, X. (1997b). EXPE: an expandable programming language for on-line psychological experiments. Behavior Research Methods, Instruments, \& Computers, 29(3), 322-327.

Pisoni, D., \& Tash, J. (1974). Reaction times to comparisons within and across phonetic categories. Perception and Psychophysics, 15(2), 285-290.

Pisoni, D. B. (1996). Some thoughts on "normalization" in speech perception. In K. Johnson \& J. W. Mullennix (Eds.), Talker variability in speech processing . San Diego: Academic Press.

Polivanov, E. (1932). La perception des sons d'une langue étrangère. Travaux du Cercle Linguistique de Prague, 4, 79-96.

Schacter, D.L. \& Church, B. (1992). Auditory priming: Implicit and explicit memory for words and voices. Journal of Experimental Psychology: Learning, Memory and Cognition, 18, 915-930.

Sebastián-Gallés, N., \& Soto-Faraco, S. (1999). On-line processing of native and non-native phonemic contrasts in early bilinguals. Cognition, 72, 112-123. Strange, W. (1995). Cross-language studies of speech perception: a historical review. In W. Strange (Ed.) Speech Perception and Linguistic Experience, (pp. 3-48). Baltimore, MD: York Press.

Trubetzkoy, N. (1939/1969). Principles of Phonology (C.A. Baltaxe, Trans.). Berkeley, CA: University of California Press.

Werker, J. F., \& Tees, R. C. (1984). Cross-language speech perception: Evidence for perceptual reorganization during the first year of life. Infant Behavior and Development, 7, 49-63.
Catalan-specific contrasts

e- $\varepsilon$ :

Pere-pera (Peter-pear), seva-ceba (his/hers/theirs-onion), déu-deu (god-ten), néta-neta (granddaughter-clean f.), vénen-venen (they come/ they sell), seré-serè (I will be-calm m.), que-què (that/what), més-mes (more-month)

o-ग

ossos-òssos (bears-bones), dóna-dona (s/he giveswoman), molta-mòlta (a lot f., powdered), sol-sòl (sunground), sóc-soc (I am-log), són-son (they are-sleep noun), rossa-rosa (blonde-pink), sota-sota (under-jack)

$\mathrm{S}-\mathrm{Z}$

caça-casa (hunting-house), cinc-zinc (five-zinc), vessarbesar (to pour-to kiss), passar- pesar (to pass-to weight), peça-pesa (piece-weight (noun)), cel-zel (sky-zeal), sonazona (sounds (verb)-zone), calces-calzes (panties-cups)

Common contrasts

capa-cava (cape-wine cellar), tia-dia (aunt-day), sogasoda (rope-soda), pala-bala (shovel-bullet), gala-cala (full dress-cove), pot-bot (pot-boat), gata-bata (cat-dressing gown), gol-bol (goal-bowl)

\section{Appendix}

Experimental stimuli. 